\title{
Erratum to: Advances in Network and Distributed Systems Security
}

Bart De Decker ${ }^{1}$, Frank Piessens ${ }^{1}$, Jan Smits $^{2}$, and Els Van Herreweghen ${ }^{3}$

1 Katholieke Universiteit Leuven, DistriNet, Belgium

2 Technische Universiteit, Eindhoven, The Netherlands

${ }^{3}$ IBM Research Laboratory, Zürich, Switzerland

\section{Erratum to:}

B. De Decker et al. (Eds.)

Advances in Network and Distributed Systems Security

DOI: $10.1007 / 978-0-306-46958-9$

The book was inadvertently published with an incorrect name of the copyright holder. The name of the copyright holder for this book is: (c) IFIP International Federation for Information Processing. The book has been updated with the changes.

The updated original online version for this book can be found at DOI: $10.1007 / 978-0-306-46958-9$ 